\title{
Face-to-face emotion interaction studies in Down syndrome infants
}

\author{
Fernando Carvajal and Jaime Iglesias \\ Universidad Autónoma de Madrid, Spain
}

\begin{abstract}
Infants with Down syndrome constitute an ideal population for analysing the development of emotional expression from the first months of life, due basically to the fact that this chromosomal alteration is identifiable from birth and results in well-known difficulties of cognitive development and in basic learning processes. Taking into account the functional aspects of facial expression during initial social interaction, in this review we present a series of studies which, although based on different theoretical approaches and different methodologies, have the common objective of analysing the emotional behaviour of young infants with and without Down syndrome during faceto-face interaction with their mothers. The main conclusions emerging from these studies are: (a) that, as in the case of typically developing infants, Down syndrome infants and their mothers present a series of coordinated and interdependent expressive interchanges; (b) that, despite the differences found between infants with and without Down syndrome in quantitative parameters of expressive behaviour, such as frequency, duration and intensity of the different emotional expressions or their point of initiation in development, what seems to be most significant is the clear functional similarity observed in the two groups of subjects during initial mother-infant interaction; and (c) that these differences may be understood by considering different psychobiological explanations as well as the known cognitive deficits.
\end{abstract}

It has been suggested that social interaction during the first year affects the regulation of the corticolimbic systems, thus determining to a large extent normal and pathological emotional development (Feldman, Greenbaum, \& Yirmiya, 1999; Kopp, 1982; Maccoby, 1992; Schore, 1996). Specifically, the study of facial expression exchanges during early social interaction is of enormous importance for analysing the role of emotion in psychological development. In accordance with this, a constant feature in our research has been the study of the basic abilities of expression and recognition of emotions in infants, one of our principal objectives being the functional analysis of these abilities during natural mother-infant face-toface interaction (Carvajal \& Iglesias, 1997, 2000; Carvajal, Loeches, \& Iglesias, 1989; Iglesias, Loeches, \& Serrano, 1989; Iglesias, Naranjo, Peláez, Becerra, \& Loeches, 1984; Serrano, Iglesias, \& Loeches, 1992, 1995). The assumptions on which such mother-infant interaction studies are based have varied according to different theoretical positions, being most notable in recent years, as far as the field of emotion is concerned, those carried out from a neo-Darwinist perspective.

This psychobiological approach emphasises the existence of a small number of basic emotions, among which are generally included joy, anger, fear, sadness, disgust, and surprise. It is assumed that these emotions are initially regulated by subcortical circuits of neurones, that these circuits are specific to each emotion and that their activity involves discrete subjective, vegetative, and motor changes, emphasising the universality of certain facial expressions and their communicative function (see, e.g., Ekman \& Friesen, 1975; Izard,
1977, 1991; Panksepp, 1982; Tomkins, 1962, 1963). In this respect, the neo-Darwinist theories of emotion lead us to assume the phylogenetic origin of each facial expression, but also to the investigation of how the learning of social display rules influences the change of facial sign by facial symbols of affective communication, taking into account that both the facial expressions of emotion and their stimuli vary during ontogeny, giving rise to important individual and cultural differences (Eibl-Eibesfeldt, 1975, 1989; Ekman \& Friesen, 1975; Malatesta, Grigoryev, Lamb, Albin, \& Culver, 1986; Ortega, Iglesias, Fernández-Dols, \& Corraliza, 1983).

Considering, then, initial facial signs of emotion, it is crucial to assume in early infancy the existence of an innate concordance between the subjective feeling and the objective facial expression characteristic of each basic emotion, and that this concordance ensures communication between the infant and the persons around him/her (see, e.g., Izard, 1991). Taking as given that expressive behaviour constitutes a reliable index of the infant's subjective feeling and a variable that largely determines the behaviour of the mother or caregiver, these authors underline the importance of studies on the development of emotional facial expression in young infants for increasing our understanding of typical and pathological emotional development (see, e.g., Izard \& Malatesta, 1987).

Within this theoretical background, it is especially interesting to make comparative studies of the facial expression of typically developing infants with that of infants exhibiting alterations in their development. However, in cases such as that of infantile autism, given the difficulty of detecting
Correspondence should be addressed to Dr Fernando Carvajal, Departamento de Psicología Biológica y de la Salud. Facultad de Psicología, Universidad Autónoma de Madrid, 28049 Madrid, Spain; e-mail: fernando.carvajal@uam.es
This research was supported by a grant from the Dirección General de Enseñanza Superior (proyecto PB95-0246) del Ministerio de Educación y Cultura de España. 
alterations before the age of three, the majority of such studies consist in retrospective parental accounts and home videos where available (Gillberg et al., 1990; Osterling \& Dawson, 1994), except in those rare cases in which prospective studies of particular subjects are carried out (Charman et al., 1997). The case of Down syndrome is a special one, because this chromosomal alteration is generally detected at birth, affects a relatively large proportion of the population and is etiologically homogeneous, though (as occurs in the general population) heterogeneous in terms of phenotype, so that it constitutes an interesting natural model for the study of emotional development (Cicchetti \& Beeghly, 1990; Cicchetti \& Sroufe, 1976, 1978; Emde, Katz, \& Thorpe, 1978). Accordingly, Down syndrome infants have demonstrated slower and restricted cortical development from birth, reflected in difficulties in the basic processes of learning and memory, and particularly in language development and the conventional expression of emotions (see, among others, Carlesimo, Marotta \& Vicari, 1997; Karmiloff-Smith, Klima, Bellugi, Grant, \& BaronCohen, 1995; Kernan \& Sabsay, 1996; Ohr \& Fagen, 1994). Nevertheless, spontaneous facial expression and the process of emotional development, particularly in terms of the nature of the stimuli that provoke the appearance of these emotional expressions at each stage of development, is found to be comparable to that of typically developing infants, at least during the first year of life (Cicchetti \& Sroufe, 1976; Emde \& Brown, 1978). In other words, the comparative study of the development of early emotional expression in infants with and without Down syndrome should allow us to analyse the role of social learning in the development of emotional expression and, naturally, to gain deeper knowledge of the characteristics of this alteration.

\section{Early empirical studies on facial expression in infants with Down syndrome}

A review shows us that, as with typically developing subjects, the first empirical studies on facial expression in Down syndrome infants consisted in the analysis of adult subjects' impressions on the basis of photographs or the direct codification of infants' facial behaviour using observation codes; the former type have been called judgement studies, and the latter, component studies (for reviews, see Ekman \& Oster, 1979; Hiatt, Campos, \& Emde, 1979; Izard \& Dougherty, 1982).

Judgement studies have a longer tradition, and generally include inferential responses such as smiling and laughing, and to a lesser extent crying, fear and interest. From these studies it is deduced that the facial expressions of Down syndrome infants, compared to those of typically developing children, are more difficult to assess and, more specifically, that: (a) Both smiling and laughter begin later and present lower frequency, duration, and intensity; and (b) negative emotions in Down syndrome infants are presented with a delay with respect to those of typically developing infants (Berger \& Cunningham, 1986; Buckhalt, Rutherford \& Goldberg, 1978; Carvajal et al., 1989; Cicchetti \& Sroufe, 1976, 1978; Emde \& Brown, 1978; Emde et al., 1978; Iglesias et al., 1989; Rothbart \& Hanson, 1983; Sorce \& Emde, 1982). Nevertheless, the principal conclusion that can be reached on the basis of these studies is that, even though infants and young children with Down syndrome do not function in an identical way to their cognitively matched counterparts, emotional development does appear to be adaptive and organised, similar to the case of typically developing infants (Cicchetti \& Beeghly, 1990; Ganiban, Wagner, \& Cicchetti, 1990).

In component studies, observers must codify the facial changes that characterise a particular emotional expression. Among these codes, the most important are Ekman and Friesen's FACS (1978) and Izard's MAX (1979). In contrast to MAX, which is concerned with identifying prototypical configurations of different emotions, the FACS allows us to describe each facial expression with greater comprehensiveness and precision through the objective analysis of changes in configuration of the muscles involved (a version of this code named Baby FACS can be reached from Oster \& Rosenstein, in press). Through the use of the FACS observational code, it has been discovered that there exist, from the first moments of life, distinctive facial patterns for joy, anger, fear, sadness, surprise, and disgust, both in typically developing infants and in Down syndrome infants, and that these patterns involve the same neuromuscular base as is employed in the emotional expression of adult subjects; additionally, the temporal organisation of expressive movements appears to be the same in infants and adults, at least as far as the facial actions of the social smile are concerned (Camras et al., 1998; Carvajal et al., 1989; Iglesias et al., 1984, 1989; Oster, 1978).

The majority of studies developed on these lines are not sufficiently conclusive, as they are basically limited to a description of the morphological configuration of infantile facial expression. In order to understand emotional development, it would be necessary to study similarities in frequency of these emotional displays, rate of response to social and nonsocial stimuli, and response time, reaction time, and kind of reactions of the social partner (i.e., the functional characteristics of facial features). It is precisely for this reason that the best situation for studying this complex pattern in early real-life situations would be mother-infant face-to-face interaction, which constitutes the main object of study of the works we review in detail below.

\section{Mother-infant face-to-face emotion interaction studies in Down syndrome infants}

As indicated above, studies on mother-infant interaction and emotion development allow us to assess the association between the expressive behaviour of the child and the adult and, consequently, the way in which emotional expressions represent particular forms of response to the behaviour of others that are susceptible to modification through social learning. Because the studies carried out in this field differ from one another in terms of the precise theoretical problem to be investigated and the methodology employed, it must be stressed that the only common denominator is the interest in analysing to some extent emotional behaviour during early mother-child exchanges, almost always with respect to development that is considered normal.

We take as a starting point the work of Tomkins (1962, 1963) and its influence on the important research carried out on facial expression and emotion by Izard and by Ekman and Friesen in the 1970s (Ekman \& Friesen, 1975; Izard, 1971), as well as the various traditions of developmental research founded by Werner, Piaget, Vygotsky, and Spitz (Piaget \& Inhelder, 1947; Spitz, 1945; Vygotsky, 1962; Werner, 1948) 
and continued by, among others, Zigler, Sroufe, Emde, Campos, and Cicchetti (Campos, Emde, Gaensbauer, \& Henderson, 1972; Cicchetti \& Sroufe, 1978; Emde \& Brown, 1978; Zigler, 1967), which deal to a greater or lesser extent with the importance of emotion in psychosocial development. In this section we review the studies published in the last 20 years that deal with mother-infant interaction and emotional expression in infants with Down syndrome; Table 1 shows the general characteristics of the sample and methodology employed in the 19 studies reviewed. Although they may be cited in the text, no studies that do not include samples of Down syndrome infants are shown in the table; nor are studies with Down syndrome infants that: (a) do not analyse aspects directly related to emotion; (b) are based on judgements from photographs taken from interaction sequences, without examining the relationship established between the behaviour of the child and the adult; (c) focus on children over two years old; and (d) are unpublished, or have been published only in the form of an abstract or a brief explanation in a chapter of a book, with the exception of the work by Cunningham and Berger (cited in Berger, 1990), which is included because it is the only study on maternal imitation with Down syndrome infants, making it especially interesting for defining differences between infants with and without Down syndrome in response to the behaviour of their mothers.

\section{Precautions to be observed in relation to age of subjects and characteristics of the interaction}

A first consideration involves age. If we consider that the period in which a child is considered to be an "infant" covers the two first years of life, it should be borne in mind that the criterion for the selection of subjects varies across studies, according to whether we are considering the first or the second year. In the first year, there is a tendency to pair infants with and without Down syndrome according to chronological age (see, e.g., Berger \& Cunningham, 1981), whilst in the second year the pairing tends to be made as a function of mental age, so that in this case, the typically developing infants have a lower chronological age (see, e.g., Mundy, Sigman, Kasari, \& Yirmilla, 1988). Authors should take into account, therefore, the point at which the development of Down syndrome infants begins to differ from that of typically developing infants, and the factors related to this divergence. In this regard, we consider that around age 6 months important cognitive changes take place in typically developing infants that may not affect to the same extent those with Down syndrome (Carvajal \& Iglesias, 1997; Izard, 1979; Ohr \& Fagen, 1994).

Second, all of these studies generally tend to consider the interaction between the child and his/her mother, and only occasionally, and in complementary fashion, between the child and another person in his/her environment, be it the father, the caregiver or a stranger (see, e.g., Legerstee \& Bowman, 1989). In any case, as appreciated in Table 1 , it should be stressed that: (1) the majority of studies have been carried out in laboratories, with very few taking place in homes; (2) toys are to hand in most studies, and only in a few are there no data about them available or is their use prohibited; and (3) although in some cases there are no data available, generally, the child sat in front of his/her mother so that she was able to position the infant in the way she considered most comfortable for interaction. As far as the possible influence of these three situational variables (place in which the interaction occurs, absence or availability of objects and position adopted by the infant) on results, we feel it appropriate to mention the works of O'Brien, Johnson, and Anderson-Goetz (1989) and of Fogel, Young, and McEwen (1992).

O'Brien et al. (1989), who designed two complementary studies with scales of interaction, observed that: (a) there were no differences between the scores obtained at home and in the laboratory when in each case toys were available; and (b) although parameters, such as frequency of positive or negative maternal expressions or quantity and nature of vocalisations emitted by mothers remain constant, in general, higher scores were obtained in the laboratory than at home when toys were not available, which, according to the authors may indicate that in the laboratory mothers felt obliged to "put on a show". Given that mothers usually use toys during interaction and that location scarcely has an influence when they are available, we believe it is clearly demonstrated that the presence of toys leads to a more natural form of interaction, independently of the place in which the observations are carried out. As regards the position of the child, Fogel et al. (1992) find that the younger infants look at their mother's face more in a prostrate position than in a seated position. Because, as we shall see later, direction of gaze can be a key element in mother-child interaction, it appears that choice by the mother of the position adopted by the infant may be an essential component in the system of facial interaction, and may be varied by her according to the stage of the infant's development. In conclusion, we believe that future research should take more account of the mother's behaviour, especially if in natural conditions mothers of infants with and without Down syndrome provide a similar kind of stimulation and if the possible variations that can be observed in typical interaction conditions have different consequences for the behaviour of infants with and without Down syndrome. Below we shall describe the different approaches of the interaction studies reviewed.

\section{Naturalistic and experimental approaches}

The most interesting specific characteristics of each sample and the different methodologies employed are shown in Table 1. As it can be seen, the majority of the studies reviewed have been carried out in conditions of natural interaction. In general, they focus on determining the range of behaviours exhibited by infants and their mothers or caregivers, as well as the mother-child expressive contingencies and their variations over the course of development. In the majority of cases the aim is to assess which aspects of the mother's interactive behaviour are relevant for the early social development of the child; some studies aim to describe certain indicators of child emotional development, using the procedure known as the Ainsworth Strange Situation. Finally, there are some experimental studies in which the facial behaviour of the mother is manipulated, where there is generally a combination of natural interaction episodes with others in which the mother receives instructions to behave in a way that is different from her normal behaviour. We consider that these three types of study, though complementary, involve different initial approaches and have different implications with regard to the emotional development of children with Down syndrome. We shall therefore review them separately. 
Table 1

Characteristics of sample and methodology of studies on mother-infant interaction in Down syndrome infants

\begin{tabular}{|c|c|c|}
\hline Authors/Year & Sample & Procedure \\
\hline Cook \& Culp (1981) & $\begin{array}{l}16 \mathrm{DS} \text { ( } 20 \text { months) and } 16 \mathrm{TD} \text { (12 months) } \\
\text { matched in MA }\end{array}$ & $\begin{array}{l}\text { Interaction in the lab with toys new to infant } \\
\text { (15 min) }\end{array}$ \\
\hline Berger \& Cunningham (1981) & $\begin{array}{l}5 \mathrm{DS} \text { and } 7 \mathrm{TD} \text { matched in } \mathrm{CA} \\
(1.5-6 \text { months })\end{array}$ & $\begin{array}{l}\text { Two episodes of } 1 \mathrm{~min} \text { at home: (1) natural } \\
\text { interaction; and (2) still-face condition }\end{array}$ \\
\hline Gunn, Berry \& Andrews (1982) & $\begin{array}{l}11 \mathrm{DS} \text { and } 11 \mathrm{TD} \text { matched in CA } \\
\text { (6-9 months) }\end{array}$ & $\begin{array}{l}\text { Interaction in the lab without toys } \\
(3 \mathrm{~min})\end{array}$ \\
\hline Brooks-Gunn \& Lewis (1984) & $\begin{array}{l}56 \mathrm{DS}, 34 \mathrm{CP} \text {, and } 21 \mathrm{DD} \text { matched } \\
\text { in CA (3-36 months) }\end{array}$ & $\begin{array}{l}\text { Natural interaction in the lab with toys } \\
(15 \mathrm{~min})\end{array}$ \\
\hline
\end{tabular}

Thompson, Ciccetti, Lamb, \& Malkin (1985)

$26 \mathrm{DS}$ (CA $=19$ months) and $43 \mathrm{TD}$ observed at 12.5 months (i.e., matched in MA) and at 19.5 months (i.e., matched in CA)

Berger \& Cunningham (1986)

Similar to Berger \& Cunningham (1981)

Ainsworth Strange Situation procedure in lab

Mundy, Sigman, Kasari, \& Yirmiya (1988)

30 DS (22.9-43 months)

30 TD (15.2-22.6 months)

matched in MA

Similar to Berger \& Cunningham (1981)

Interation in the lab: (1) with an experimenter showing various toys to the child (25 $\mathrm{min}$ ); (2) natural interaction with the mother without toys ( $4 \mathrm{~min}$ ); and (3) four episodes of natural interaction with the mother with four different types of toy

Six episodes of $1 \mathrm{~min}$ in the lab: (1) natural interaction with the mother; (2) natural interaction with stranger; (3) still-face condition with the mother; (4) still-face condition with the stranger; (5) interaction with static toys; and (6) interaction with mobile toys

Landry \& Chapieski (1989, 1990)

Cunningham \& Berger (cited in Berger, 1990)

Kasari, Mundy, Yirmiya, \& Sigman (1990)

Crown, Feldstein, Jasnow, Beebe, \& Jaffe (1992)

Knieps, Walden, \& Baxter (1994)

Kasari, Freeman, Mundy, \& Sigman (1995)

Harris, Kasari, \& Sigman (1996)

Legerstee \& Weintraub (1997)

Carvajal \& Iglesias $(1997,2000)$
14 DS and 15 premature TD matched in CA (12 months)

$12 \mathrm{DS}$ and $12 \mathrm{TD}$ matched in CA (5-7 months)

Similar to Mundy et al. (1988)

$10 \mathrm{DS}$ and $11 \mathrm{TD}$ matched in CA (4-9 months)

11 DS (15-41 months) and 11 TD (10-23 months) matched in MA

35 DS (13-42 months) and 23 TD (9-27 months) matched in MA
Natural interaction in the lab with toys $(10 \mathrm{~min})$

Two episodes of $2 \mathrm{~min}$ : (1) natural interaction; and (2) imitation

Similar to Mundy et al. (1988)

Natural interaction in the lab for $12-15 \mathrm{~min}$; with 9-month-olds the mothers had a hand puppet available

In the lab, emotional poses of joy and fear by mother or father in the presence of 2 different remote-controlled mechanical toys (7 episodes $20 \mathrm{~s}$ with each expression for each toy)

Interaction in the lab: (1) with experimenter while showing various toys to child; and (2) father or mother and experimenter showing expressions of fear or joy at same time as remote-controlled robot enters room (30 s)

Natural interaction in the lab with mother or father $(5 \mathrm{~min})$ and with toys

Three episodes of $5 \mathrm{~min}$ at home with toys: (1) interaction with the mother; (2) interaction with peer's mother; (3) interaction with peer

Two episodes at home: (1) natural interaction (15 min); and (2) still-face condition (1-2 min)

Note: Abbreviations: DS (infants with Down syndrome); TD (typically developing infants); CP (infants with cerebral palsy); DD (infants with developmental delays whose etiology was unknown); CA (chronological age); MA (mental age). 


\section{Natural interaction studies}

It is important to begin by pointing out that, in terms of what is understood in the scientific literature as natural interaction, there are a variety of views: some authors consider natural faceto-face interaction as a continuum of mutual looks, smiles and touches, not mediated by physical objects (Fogel et al., 1992), whilst others define it as a situation where the behaviour of the infant or mother is contingent upon the prior behaviour of the other (Berger, 1990). Bearing in mind that interaction is usually mediated not only by the face but also by other objects in the environment, we feel that the first definition could be too restrictive. Therefore, when we speak here of natural interaction we do so in the sense of Berger's definition.

Bearing this in mind, and concentrating on the facial expression of the infants, we find that the various authors coincide in pointing out that during natural interaction infants with and without Down syndrome are capable of showing specific facial patterns associated with different basic emotions, the smile being the most frequent facial expression in these episodes (Carvajal \& Iglesias, 1997; Iglesias et al., 1989; Malatesta, Culver, Tesman, \& Shepard, 1989; Malatesta \& Haviland, 1982; Matias \& Cohn, 1993; Toda \& Fogel, 1993; Weinberg \& Tronick, 1994). It is also emphasised that there are changes in the expressive behaviour of the infant throughout development, with an increase in the total quantity of positive expressions and a decrease in the frequency of negative expressions, both in typically developing and Down syndrome children (Brooks-Gunn \& Lewis, 1984; Malatesta et al., 1986).

With respect to variables such as direction of gaze, vocalisations, and body movements, variables that are useful for establishing additional criteria of internal validity and which sometimes constitute key elements for determining the social context of the expressions, the most often considered of these has been direction of gaze. In both typically developing and Down syndrome infants there is a drastic decrease in the time during which infants look at their mother's face throughout the first year of life, which indicates that, in the course of development, interaction is modulated more and more by the different elements of the environment (Carvajal \& Iglesias, 2000; Malatesta et al., 1986). In the same way, although eye contact begins later in Down syndrome infants, it is clear that the developmental scheme of direction of gaze follows a similar sequence in typically developing and Down syndrome children, even if in general, Down syndrome infants look more at their mothers (Berger \& Cunningham, 1981; Carvajal \& Iglesias, 2000; Crown, Feldstein, Jasnow, Beebe, \& Jaffe, 1992; Gunn, Berry, \& Andrews, 1982) or at the experimenter's face (Kasari, Mundy, Yirmiya, \& Sigman, 1990) than typically developing infants and, from the second year, Down syndrome children look less at toys than typically developing infants of the same mental age (Harris, Kasari, \& Sigman, 1996; Kasari, Freeman, Mundy, \& Sigman, 1995; Kasari et al., 1990; Landry \& Chapiesky, 1989, 1990; Legerstee \& Weintraub, 1997; Mundy et al., 1988).

As regards the organisation of the mother's behaviour, the first thing to point out is that the works reviewed here do not focus on the mother's behaviour as such, but consider it basically as a reference for the behaviour of the infant. Bearing this in mind, the most notable finding is that mothers, as well as employing verbal strategies and tactile behaviours as ways of stimulating the infant, express almost exclusively positive emotions and spend the majority of the time looking at the infant's face (Carter, Mayes, \& Pajer, 1990; Carvajal \& Iglesias, 1997, 2000; Gunn et al., 1982; Malatesta \& Haviland, 1982). Moreover, although it has been suggested as a possibility that the behaviour of mothers of Down syndrome infants is more directive than that of mothers with typically developing children, in the sense that they may more frequently attempt to orientate the child's attention, in general terms no important differences are found between the facial actions of mothers that can be attributed to either chronological age or to chromosomal condition of infants (Berger \& Cunningham, 1986; Brooks-Gunn \& Lewis, 1984; Carvajal \& Iglesias, 1997; Cook \& Culp, 1981; Gunn et al., 1982; Landry \& Chapiesky, 1989, 1990).

As far as the organisation of sequences of mother-child interaction is concerned, as we have already pointed out, the process of face-to-face natural interaction between infants and mothers involves the possibility that one of the two members of the pair may influence in a significant way the behaviour of the other. Up to the present, the various authors have only coincided in pointing out: (a) that neither the behaviour of the child nor that of the mother is random, but rather that they exhibit a coordinated sequence that makes communication possible, and (b) that with age a greater covariance is observed between the child's and the mother's behaviour (Malatesta \& Haviland, 1982; Malatesta et al., 1986; Nwokah, Hsu, \& Fogel, 1994). When we attempt to establish the direction of the influence of emotional expression, important discrepancies are found. Some authors defend the idea that it is the child's positive expression that makes the mother respond in the same direction (Malatesta \& Haviland, 1982; Malatesta et al., 1986; Nwokah et al., 1994). Our research suggests that the onset of the infant's smile precedes the onset of the mother's smile, moreover, from age six months, in typically developing children, the probability that the mother's smile precedes the infant's increases (Carvajal \& Iglesias, 1997). Other authors, however, consider, at least during the first nine months of life, that it is the mother who captures the attention of the infant through tactile stimulation, and that it is her positive expression that precedes that of the child; thus, when the infant beings to smile, the mother continues smiling until the child terminates the sequence (Cohn \& Tronick, 1987, 1988; Tronick \& Cohn, 1989).

\section{Ainsworth Strange Situation studies}

The procedure of reaction to a stranger (see Ainsworth, Blehar, Waters, \& Wall, 1978; Ainsworth \& Wittig, 1969; Bretherton \& Ainsworth, 1974, among others) consists in the following sequence of seven 3-minute episodes in the laboratory: (a) the mother and her infant interact alone in the playroom; (b) a stranger enters the room and interacts with the mother and the infant; (c) the mother leaves the room and the stranger interacts with the infant; (d) the mother enters the room once again to be with the infant and the stranger leaves; (e) the mother leaves the room again and the infant is left alone; ( $f$ ) the stranger returns; and (g) the mother is reunited with the infant once more, and the stranger leaves. Through this procedure we can look for a possible relationship between emotional indicators of a general nature in the child or the mother and the type of facial expression and behavioural tendency observed during interaction (see Bretherton, 1987; Izard, Haynes, Chisholm, \& Baak, 1991; Sroufe, 1985, among others). 
The only work to compare infants with and without Down syndrome using the Ainsworth Strange Situation is that of Thompson, Cicchetti, Lamb, and Malkin (1985), who concluded that infants with and without Down syndrome present appropriate responses in the different episodes, even if Down syndrome infants show less intense separation distress, a longer onset latency and a quicker recovery in comparison to typically developing infants. This result is consistent with those found in Down syndrome children over two years old (Berry, Gunn, \& Andrew, 1980; Cicchetti \& Serafica, 1981).

\section{Experimental studies in which the facial behaviour of the adult is manipulated}

The general assumption upon which this research is based is that, in situations of natural interaction, when the mother or another adult looks and smiles at the child, if the child tends to respond with a smile, then we should suppose that when the adult behaves in another way, the infant will vary his/her behaviour in a contingent way and exhibit a different expression. As we have already indicated, in order to precisely analyse this dependent relation, instructions are given to the mother to behave in a certain way during the interaction. This manipulated behaviour may consist in simulating an emotional expression, imitating the infant or maintaining her gaze fixed on the child, making no movements or sounds or attempting to keep the infant's gaze directed towards her.

From the studies of this type carried out with samples of Down syndrome infants, we shall first consider the results when the mother remains still, looking at her child's face without emitting any type of vocalisation (in accordance with the Still-Face procedure proposed by Tronicks, Als, Adamson, Wise, \& Brazelton, 1978). These studies are designed to ascertain whether infants respond to the mother's face in a general way or whether they respond specifically to the expressive changes they observe in her face. In this case, typically developing infants show fewer smiles and, when the episodes are sufficiently long, also show more expressions of anger or annoyance (e.g., Braungart-Rieker, Garwood, Powers, \& Notaro, 1998; Gusella, Muir, \& Tronick, 1988; Kisilevsky et al., 1998; Legerstee, Corter, \& Kienapple, 1990; Stack \& Muir, 1992; Toda \& Fogel, 1993; Weiberg \& Tronick, 1994). This same result is found when the child, instead of interacting with the mother, does so with the father or with strangers in conditions with and without contact (BraungartRieker et al., 1998; Ellsworth, Muir, \& Hains, 1993; Hernández \& Carter, 1996; Kisilevsky et al., 1998; Stack \& Muir, 1992). Moreover, it would appear that the emotional expression of the infant during natural interaction is a good predictor of his/her later emotional behaviour in the still-face condition, and that the infants who show themselves to be most confident during interaction show fewer negative emotions and more positive ones, whilst the more insecure infants show more negative emotions (Carter et al., 1990). However, in the case of Down syndrome infants, while some authors find results that are similar but with a certain developmental delay (Legerstee \& Bowman, 1989), other emphasise the fact that Down syndrome infants appear less sensitive to the changes in their mother's behaviour (Berger \& Cunningham, 1986; Carvajal \& Iglesias, 1997).

Second, there are studies of "emotional poses", which consist in asking the mother or caregiver to look at the child whilst expressing an emotion indicated by the experimenter.
The object of these studies is to discover whether the facial expression of a model may influence the infant's affective state, which may manifest itself in its facial behaviour or in its action tendency with respect to a new toy. These studies show that typically developing children exhibit expressions and behavioural tendencies that are congruent with those of the person with which they are interacting (Camras \& Sachs, 1991; D'Entremont \& Muir, 1997; Haviland \& Lelwica, 1987; Knieps, Walden, \& Baxter, 1994). The only studies that employ this methodology with Down syndrome infants conclude: (1) that these infants exhibit facial expressions that are incongruent with that of their parents, given that they express positive emotions when their parents express fear and negative emotions when they pose expressions of joy or happiness, even though the expression of infants with and without Down syndrome is equal in terms of lability and intensity (Knieps et al., 1994); (2) that although Down syndrome infants look more at the adult's face and less at a toy (remote-controlled robot) than typically developing infants, nevertheless, the same tendency is observed in infants with and without Down syndrome, as both look more at the toy and less at the adult when the latter poses an emotion of joy than when he/she poses an emotion of fear; moreover, it is observed that children with Down syndrome with higher cognitive and language abilities spend more time looking at the toy (Kasari et al., 1995).

Third, in research in which the mother is asked to imitate her child, it is intended that the mother responds in a way that is highly contingent upon the infant's behaviour. On comparing episodes of natural interaction with episodes of imitation, it is found that typically developing infants smile less in the episode of imitation (Symons \& Moran, 1987) or that there are no significant differences between the two types of episode (Cunningham \& Berger, cited in Berger 1990), whilst Down syndrome infants smile and vocalise more frequently in imitation episodes (Cunningham \& Berger, cited in Berger 1990). According to these last-named authors, these differences may be due to the fact that Down syndrome infants need a greater quantity of responses of a contingent nature from their mothers; in consequence, the increase in the contingency of maternal response would induce little change in the behaviour of typically developing infants, but it may, on the other hand, lead to the response of Down syndrome infants being more effective.

\section{Conclusions and final comments}

With regard to emotional development, we can conclude that, during face-to-face interaction episodes, infants with and without Down syndrome and their mothers exhibit a series of facial actions and behavioural changes that are coordinated and interdependent. Although there are some differences in the behaviour of infants according to their chromosomal condition, the most important conclusion we would like to underline here is that the process of emotional interaction develops in a similar way in infants with and without Down syndrome, thus reinforcing the thesis of functional equivalence in the emotional expression of infants with and without Down syndrome (Cicchetti \& Beeghly, 1990; Cicchetti \& Sroufe, 1976, 1978, among others).

We would also like to emphasise that responses such as emotional expressions are initially under subcortical control. 
Consequently, cognitive factors alone would not explain the differences observed between infants with and without Down syndrome in parameters, such as frequency, duration, and intensity of the different emotional expressions or their point at which they appear; in fact, these differences are found even when infants with and without Down syndrome are matched in terms of level of development. In relation to this, it has traditionally been stressed that Down syndrome children present considerable psychomotor retardation due to two factors: (1) the generalised muscular hypotonia that is evident from birth - infants diagnosed as extremely hypotonic may have greater difficulties for engaging in and reacting to environmental events (Cowie, 1970; Henderson, 1985; McIntire \& Dutch, 1964); and (2) deficiencies in sensorimotor integration related to visual feedback on postural stabilityvisual propioception - so that it has been observed that infants with and without Down syndrome matched in postural capacity show differences in body stability when they are provided with discrepant visual feedback on their physical environment (Butterworth \& Cicchetti, 1978). Bearing in mind that muscle tone may influence the ability to effect expressive movements then, and that vision (independently of its fundamental role as a source of external information) contributes to calibrating the mechanical-vestibular system in relation to external stimulation, the fact that Down syndrome infants present muscular hypotony and difficulties for coordinating mechanical-vestibular and visual indices may explain why they require greater effort for producing an emotional expression (Cicchetti \& Sroufe, 1976, 1978). The consequence of such differential conditions is that Down syndrome infants may present a different baseline situation for attaining the activation required for expressing a given emotion.

Additionally, we must take into account, apart from alterations in the process of activation, possible alterations in inhibitory processes. Specifically, it has been found that primary reflexes persist for longer in Down syndrome infants (Cowie, 1970), that when Down syndrome infants become aroused they have difficulty in "shutting down" their responses, and that they show a higher frequency of reflex responses, such as blinking when faced with external stimulation (Cicchetti \& Sroufe, 1978). In sum, these alternative explanations lead us to consider that the differences observed in quantitative parameters of early emotional expression in Down syndrome with respect to typically developing infants should not be reduced to a cognitive impairment, but rather related to general difficulties associated with the modulation of emotional phasic arousal, which would include both activatory processes dependent on central and peripheral mechanisms and processes of forebrain inhibitory control (for a review see Cicchetti \& Sroufe, 1978; Ganiban et al., 1990; Thompson et al., 1985).

Taken together, the results of the studies reviewed suggest that, in contrast to what may occur in the case of other conditions, such as some forms of autism, which cause profound impairments in socioemotional sensitivity that may coexist with intact cognitive abilities, socioemotional abilities are relatively unimpaired in Down syndrome, despite the profound impairments in cognitive development. Thus, as already mentioned, infants with this chromosomal alteration constitute an ideal population for studying the normal development of emotion, as their different cognitive abilities with respect to typically developing infants will be precisely what marks the differences in the process of social learning that allow us to better understand which elements of the environment determine the socialisation of emotional expression.

Apart from the theoretical implications opened up by this perspective, there are undoubtedly important reasons from an applied point of view for continuing to analyse early emotional interaction in Down syndrome, as this type of study may be useful for improving the relationship between children with this alteration and their parents or caregivers, who may consider them to have a lower capacity for socioemotional communication than typically developing infants (Emde et al., 1978; see also Richard, 1986; Rothbart \& Hanson, 1983; Sorce \& Emde, 1982), despite the existence of objective data showing that the interaction process occurs in a clearly similar way in infants with and without Down syndrome. Thus, bearing in mind the enormous importance of the expressive components of emotion for human communication throughout the life cycle, the relevance of encouraging the study of socioaffective behaviour in Down syndrome infants from the first moments of life is obvious. This is particularly true if we consider that, given the limits imposed by deficits of, for example, language, our perspective on Down syndrome is somehow enriched and modified by attending to nonverbal aspects, among which facial expression plays a fundamental role.

Manuscript received September 1999 Revised manuscript received June 2000

\section{References}

Ainsworth, M.D., Blehar, M.D., Waters, E., \& Wall, S. (1978). Patterns of attachment: A psychological study of the strange situation. Hillsdale, NJ: Erlbaum. Ainsworth, M.D., \& Wittig, B.A. (1969). Attachment and exploratory behavior of one-year-olds in a strange situation. In B.M. Foss (Ed.), Determinants of infant behavior (Vol. 4). London: Methuen.

Berger, J. (1990). Interactions between parents and their infants with Down syndrome. In D. Cicchetti \& M. Beeghly (Eds.), Children with Down syndrome. $A$ developmental perspective (pp. 101-146). Cambridge, UK: Cambridge University Press.

Berger, J., \& Cunningham, C.C. (1981). The development of eye contact between mothers and normal and Down's syndrome infants. Developmental Psychology, 17, 678-689.

Berger, J., \& Cunningham, C.C. (1986). Aspects of early social smiling by infants with Down's syndrome. Child: Care, Health and Development, 12, 13-24.

Berry, P., Gunn, P., \& Andrews, R. (1980). Behavior of Down syndrome infants in a strange situation. American fournal of Mental Deficiency, 85, 213-218.

Braungart-Rieker, J.B., Garwood, M., Powers, B.P., \& Notaro, P.C. (1998). Infant affect and regulation during the still-face paradigm with mothers and fathers: the role of infant characteristics and parental sensitivity. Developmental Psychology, 34, 1428-1437.

Bretherton, I. (1987). New perspectives on attachment relations: Security, communication, and internal working models. In J.D. Osofsky (Ed.), Handbook of infant development (2nd ed., pp. 1061-1100). New York: Wiley.

Bretherton, I. \& Ainsworth, M. (1974). Response of 1-year-olds to a stranger in a strange situation. In M. Lewis \& L. Rosenblum (Eds.), The origins of fear. New York: Wiley.

Brooks-Gunn, J., \& Lewis, M. (1984). Maternal responsivity in interaction s with handicapped infants. Child Development, 55, 782-793.

Buckhalt, J.A., Rutherford, R.B., \& Goldberg, K.E. (1978). Verbal and nonverbal interaction of mothers with their Down's syndrome and nonretarded infants. American fournal of Mental Deficiency, 82, 337-343.

Butterworth, G., \& Cicchetti, D. (1978). Visual calibration of posture in normal and motor retarded Down's syndrome infants. Perception, 7, 513-525.

Campos, J.J., Emde, R.N., Gaensbauer, T., \& Henderson, C. (1972). Cardiac and behavioral interrelationships in the reaction of infants to strangers. Developmental Psychology, 23, 362-371.

Camras, L.A., Campos, J., Campos, R., Miyake, K., Oster, H., Ujiie, T., Wang, L., \& Meng, Z. (1998). Production of emotional facial expressions in European American, Japanese, and Chinese infants. Developmental Psychology, 34, 616-628.

Camras, L.A., \& Sachs, V.B. (1991). Social referencing and caretaker expressive behavior in a daycare setting. Infant Behavior and Development, 14, 27-36. 
Carlesimo, G.A., Marotta, L., \& Vicari, S. (1997). Long-term memory in mental retardation: Evidence for a specific impairment in subjects with Down syndrome. Neuropsychologia, 35, 71-79.

Carter, A.S., Mayes, L.C., \& Pajer, K.A. (1990). The role of dyadic affect in play and infant sex in predicting infant response to the still-facae situation. Child Development, 61, 764-773.

Carvajal, F., \& Iglesias, J. (1997). Mother and infant smiling exchanges during face-to-face interaction in infants with and without Down syndrome. Developmental Psychobiology, 31, 277-286.

Carvajal, F., \& Iglesias, J. (2000). Looking behavior and smiling in Down syndrome infants. Fournal of Nonverbal Behavior.

Carvajal, F., Loeches, A., \& Iglesias, J. (1989). Comportamiento expresivo que antecede a la sonrisa social: Comparación entre lactantes normales y afectados por el síndrome de Down [Expressive behavior that preceded social smiling: Comparative study in normal and Down syndrome infants]. Revista de Psicología Social, 4, 275-288.

Charman, T., Swettenham, J., Baron-Cohen, S., Cox, A., Baird, G., \& Drew, A. (1997). Infants with autism: An investigation of empathy, pretend play, joint attention, and imitation. Developmental Psychology, 33, 781-789.

Cicchetti, D., \& Beeghly, M. (1990). An organizational approach to the study of Down syndrome: Contributions to an integrative theory of development. In D. Cicchetti \& M. Beeghly (Eds.), Children with Down syndrome. A developmental perspective (pp. 29-62). Cambridge, UK: Cambridge University Press.

Cicchetti, D., \& Serafica, F. (1981). The interplay among behavioral systems: Illustrations from the study of attachment, affiliation and wariness in young Down sydrome children. Developmental Psychology, 17, 36-49.

Cicchetti, D., \& Sroufe, L.A. (1976). The relationship between affective and cognitive development in Down's syndrome infants. Child Development, 47, 920-929.

Cicchetti, D., \& Sroufe, L.A. (1978). An organizational view of affect: Illustration from the study of Down's syndrome infants. In M. Lewis \& L. Rosenblum (Eds.), The development of affect (pp. 309-350). New York: Plenum.

Cohn, J.F., \& Tronick, E. (1987). Mother-infant face-to-face interaction: The sequence of dyadic states at 3, 6, and 9 months. Developmental Psychology, 23, $68-77$.

Cohn, J.F., \& Tronick, E. (1988). Mother-infant face-to-face interaction: Influence is bidirectional and unrelated to periodic cycles in either partner's behavior. Developmental psychology, 24, 386-392.

Cook, A.S., \& Culp, R.E. (1981). Mutual play of mothers with their Down's syndrome and normal infants. International fournal of Rehabilitation Research, 4, 542-544.

Cowie, V.A. (1970). A study of the early development of mongols. Oxford, UK: Pergamon.

Crown, C.L., Feldstein, S., Jasnow, M.D., Beebe, B., \& Jaffe, J. (1992). Gaze behavior of Down's syndrome and nondelayed infants in interactions with their mothers. Acta Paedopsychiatrica, 55, 51-55.

Cunningham, C.C., \& Berger, J. (cited in Berger, 1990). The effects of experimental manipulation on the mother-infant interactions of Down syndrome and non-handicapped dyads. Hester Adrian Research Centre, University of Manchester.

D'Entremont, B., \& Muir, D.W. (1997). Five-month-olds' attention and affective responses to still-faced emotional expressions. Infant Behavior and Development, 20, 563-568.

Eibl-Eibesfeldt, I. (1975). Concepts of ethology and their significance in the study of human behavior. In H.W. Stevenson, E.H. Hess, \& H.L. Rheingold (Eds.), Early behavior. Huntington: New York Krieger.

Eibl-Eibesfeldt, I. (1989). Human ethology. New York: Aldine de Gruyter.

Ekman, P., \& Friesen, W.V. (1975). Unmasking the face: A guide to recognizing emotions from facial clues. Englewood Cliffs, NJ: Prentice-Hall.

Ekman, P., \& Friesen, W.V. (1978). Facial expressions of emotion. Annual Review of Psychology, 30, 527-554.

Ekman, P., \& Oster, H. (1979). Facial expressions of emotion. Annual Review of Psychology, 30, 527-554.

Ellsworth, C.P., Muir, D.W., \& Hains, S.M.J. (1993). Social competence and person-object differentiation: An analysis of the still-face effect. Developmental Psychology, 29, 63-73.

Emde, R.N., \& Brown, C. (1978). Adaptation after birth of a Down's syndrome infant. Fournal of American Academy of Child Psychiatry, 17, 299-323.

Emde, R.N., Katz, E.L., \& Thorpe, J.K. (1978). Emotional expression in infancy: II. Early Deviations in Down syndrome. In M. Lewis \& L.A. Rosenblum (Eds.), The development of affect (pp. 351-360). London: Plenum.

Feldman, R., Greenbaum, C.W., \& Yirmiya, N. (1999). Mother-infant affect synchrony as an antecedent of the emergence of self-control. Developmental Psychology, 35, 223-231.

Fogel, A., Young, J., \& McEwen, I. (1992). Effect of postural position and reaching on gaze during mother-infant face-to-face interaction. Infant Behavior and Development, 15, 231-244.

Ganiban, J., Wagner, S., \& Cicchetti, D. (1990). Temperament and Down syndrome. In D. Cicchetti \& M. Beeghly (Eds.), Children with Down syndrome.
A developmental perspective (pp. 63-100). Cambridge, UK: Cambridge University Press.

Gillberg, C., Ehlers, S., Schaumann, H., Jakobsson, G., Dahlgren, S.O., Lindblom, R., Bagenholm, A., Tjuus, T., \& Blinder, E. (1990). Autism under age 3 years: A clinical study of 28 cases referred for autistic symptoms in infancy. Fournal of Child Psychology and Psychiatry, 31, 921-934.

Gunn, P., Berry, P., \& Andrews, R.J. (1982). Looking behavior of Down syndrome infants. American fournal of Mental Deficiency, 87, 347-350.

Gusella, J., Muir, D., \& Tronick, E. (1988). The effect of manipulating materna behavior during an interaction on 3- and 6-month-old's affect and attention. Child Development, 59, 1111-1124.

Harris, S., Kasari, C., \& Sigman, M.D. (1996). Joint attention and language gains in children with Down syndrome. American fournal on Mental Retardation, 100, 608-619.

Haviland, J.M., \& Lelwica, M. (1987). The induced affect response: 10-weekold infants' responses to three emotion expressions. Developmental Psychology, 23, 97-104.

Henderson, S. (1985). Motor skill development. In D. Lane \& B. Stradford (Eds.), Current approaches to Down's syndrome (pp. 187-218). New York: Praeger.

Hernández, F.D., \& Carter, A.S. (1996). Infant responses to mothers and fathers in the still-face paradigm. Infant Behavior and Development, 19, 502.

Hiatt, S.W., Campos, J.J., \& Emde, R.N. (1979). Facial patterning and infant emotional expression: Happiness, surprise and fear. Child Development, 50, 1020-1035.

Iglesias, J., Loeches, A., \& Serrano, J.M. (1989). Expresión facial y reconocimiento de emociones en lactantes [Facial expression and recognition of emotions in infants] Infancia y Aprendizaje, 48, 93-113.

Iglesias, J., Naranjo, J.M., Peláez, F., Becerra, A., \& Loeches, A. (1984). Les expressions faciales qui précédent le sourire et le pleur chez le nourrisson de neuf à vingt semaines [Facial expressions that preceded smiling and crying in 9- to 20-week-old infants]. In A. De Haro \& X. Espadaler (Eds.), Processus d'acquisition prècoce. Les communications. Universitat Autónoma de Barcelona et Société Française pour l'Etude du Coportement Animal.

Izard, C.E. (1971). The face of emotion. New York: Appleton.

Izard, C.E. (1977). Human emotion. New York: Plenum.

Izard, C.E. (1979). The maximally discriminative facial movement coding system $(M A X)$. Newark, DE: Instructional Resources Center, University of Delaware.

Izard, C.E. (1991). The Psychology of emotions. New York: Plenum.

Izard, C.E., \& Dougherty, L.M. (1982). Two complementary systems for measuring facial expressions in infants and children. In C.E. Izard (Ed.), Measuring emotions in infants and children. Cambridge, UK: Cambridge University Press.

Izard, C.E., Haynes, O.M., Chisholm, G., \& Baak, K. (1991). Emotional determinants of infant-mother attachment. Child Development, 62, 906-917.

Izard, C.E., \& Malatesta, C.Z. (1987). Perspectives on emotional development: Differential emotions theory of early emotional development. In J.D. Osofsky (Ed.), Handbook of infant development (2nd ed., pp. 494-554). New York: Wiley.

Karmiloff-Smith, A., Klima, E., Bellugi, U., Grant, J., Baron-Cohen, S. (1995) Is there a social module? Language, face processing, and Theory of Mind in individuals with Williams syndrome. Fournal of Cognitive Neuroscience, 7 , 196-208.

Kasari, C., Freeman, S., Mundy, P., \& Sigman, M. (1995). Attention regulation in children with Down syndrome: Coordinated joint attention and socia referencing. American fournal on Mental Retardation, 100, 128-136.

Kasari, C., Mundy, P., Yirmiya, N., \& Sigman. M. (1990). Affect and attention in children with Down syndrome. American fournal on Mental Retardation, 95, $55-67$.

Kernan, K.T., \& Sabsay, S. (1996). Linguistic and cognitive ability of adults with Down syndrome and mental retardation of unknown etiology. Fournal of Communication Disorders, 29, 401-422.

Kisilevsky, B.S., Hains, S.M.J., Lee, K., Muir, D.W., Xu, F., Fu, G., Zhao, Z.Y., \& Yang, R.L. (1998). The still-face effect in Chinese and Canadian 3- to 6-month-old infants. Developmental Psychology, 34, 629-639.

Knieps, L.J., Walden, T.A., \& Baxter, A. (1994). Affective expressions of toddlers with and without Down syndrome in a social referencing context. American fournal on Mental Retardation, 99, 301-312.

Kopp, C.B. (1982). Antecedents of self-regulation: A developmental perspective Developmental Psychology, 18, 199-214.

Landry, S.H., \& Chapieski, M.L. (1989). Joint attention and infant toy exploration: Effects of Down syndrome and prematurity. Child Development, $60,103-118$.

Landry, S.H., \& Chapieski, M.L. (1990). Joint attention of six-month-old Down syndrome and preterm infants: I. Attention to toys and mother. American fournal on Mental Retardation, 94, 488-498.

Legerstee, M., \& Bowman, T.G. (1989). The development of responses to people and a toy in infants with Down syndrome. Infant Behavior and Develoment, 12, 465-477. 
Legerstee, M., Corter, C., \& Kienapple, K. (1990). Hand, arm and facial actions of young infants to a social and nonsocial stimulus. Child Development, 61, $774-784$.

Legerstee, M., \& Weintraub, J. (1997). The integration of person and object attention in infants with and without Down syndrome. Infant Behavior and Development, 20, 71-82.

Malatesta, C.Z., Culver, C., Tesman, J.R., \& Shepard, B. (1989). The development of emotion expression during the first 2 years of life. Monographs of the Society for Research in Child Develoment, 54, 1-103.

Malatesta, C.Z., Grigoryev, P., Lamb, C., Albin, M., \& Culver, C. (1986). Emotion socialization and expressive development in preterm and full-term infants. Child Development, 57, 316-330.

Malatesta, C.Z., \& Haviland, J.M. (1982). Learning display rules: The socialization of emotion expression in infancy. Child Development, 53, 991-1003.

Maccoby, E.E. (1992). The role of parents in the socialization of children: An historical overview. Developmental Psychology, 28, 1006-1017.

McIntire, M., \& Dutch, J. (1964). Mongolism and generalized hypotonia. American fournal of Mental Deficiency, 68, 669-670.

Matias, R., \& Cohn, J.F. (1993). Are Max-specified infant facial expressions during face-to-face interaction consistent with differential emotions theory? Developmental Psychology, 29, 524-531.

Mundy, P., Sigman, M., Kasari, C., \& Yirmiya, N. (1988). Nonverbal communications skills in Down syndrome children. Child Development, 59, 235-249.

Nwokah, E.E., Hsu, H.C., \& Fogel, A. (1994). The development of laughter in mother-infant communication: Timing parameters and temporal sequences. Infant Behavior and Development, 17, 23-35.

O'Brien, M., Johnson, J.M., \& Anderson-Goetz, D. (1989). Evaluating quality in mother-infant interaction: Situational effects. Infant Behavior and Development, 12, 451-464.

Ohr, P.S., \& Fagen, J.W. (1994). Contingency learning in 9-month-old infants with Down syndrome. American fournal on Mental Retardation, 99, 74-84.

Ortega, J.E., Iglesias, J., Fernández-Dols, J.M., \& Corraliza, J.A. (1983). La expresión facial en ciegos congénitos [Facial expression in congenic blind]. Infancia y Aprendizaje, 21, 33-69.

Oster, H. (1978). Facial expression and effect development. In M. Lewis \& L.A. Rosenblum (Eds.), The development of affect (pp. 43-75). New York: Plenum.

Oster, H., \& Rosenstein, D. (in press). Baby FACS: Analyzing facial movement in infants. Palo Alto, CA: Consulting Psychologists Press.

Osterling, J., \& Dawson, G. (1994). Early recognition of children with autism: A study of first birthday home videotapes. Fournal of Autism and Developmental Disorders, 24, 247-257.

Panksepp, J. (1982). Toward a general psychobiological theory of emotions. The Behavioral and Brain Science, 5, 407-422.

Piaget, J., \& Inhelder, B. (1947). Diagnosis of mental operations and theory of intelligence. American fournal of Mental Deficiency, 51, 401-406.

Richard, N.B. (1986). Interaction between mothers and infants with Down syndrome: Infant characteristics. Topics in Early Childhood Special Education, 6, 54-71.
Rothbart, M.K., \& Hanson, M.J. (1983). A caregiver report comparison of temperamental characteristics of Down's syndrome and normal infants. Developmental Psychology, 19, 766-769.

Schore, A.N. (1996). The experience-dependen t maturation of a regulatory system in the orbital prefrontal cortex and the origin of developmenta psychopathology. Development and Psychopathology, 8, 59-87.

Serrano, J.M., Iglesias, J., \& Loeches, A. (1992). Visual discrimination and recognition of facial expressions of anger, fear, and surprise in 4- to 6-monthold infants. Developmental Psychobiology, 25, 411-425.

Serrano, J.M., Iglesias, J., \& Loeches, A. (1995). Visual fixation and overt behavior to emotion facial expressions in infants. Infant Behavior and Development, 18, 477-482.

Sorce, J.F., \& Emde, R.N. (1982). The meaning of infant emotional expressions: Regularities in caregiving responses in normal and Down syndrome infants. Fournal of Child Psychology and Psychiatry, 22, 145-158.

Spitz, R.A. (1945). Hospitalism: An inquiry into the genesis of psychiatric conditions in early childhood. Psychoanalytic Study of the Child, 1, 53-74.

Sroufe, L.A. (1985). Attachment classification from the perspective of infantcaregiver relationships and infant temperament. Child Development, 56, 1-14.

Stack, D.M., \& Muir, D.W. (1992). Adult tactile stimulation during face-to-face interaction s modulates 5-month-olds' affect and attention. Child Development, $63,1509-1525$.

Symon, D.K., \& Moran, G. (1987). The behavioral dynamics of mutual responsiveness in early face-to-face mother-infant interactions. Child Development, 58, 1488-1495.

Thompson, R., Cicchetti, D., Lamb, M., \& Malkin, C. (1985). The emotional responses of Down syndrome and normal infants in the Strange Situation: The organization of affective behavior in infants. Developmental Psychology, 21, 828-841.

Toda, S., \& Fogel, A. (1993). Infant response to the still face situation at 3 and 6 months. Developmental Psychology, 29, 532-538.

Tomkins, S.S. (1962). Affects, imagery, and consciousness: Vol. 1. The positive affects. New York: Springer.

Tomkins, S.S. (1963). Affects, imagery, and consciousness: Vol. 2. The positive affects. New York: Springer.

Tronick, E.Z., Als, H., Adamson, L., Wise, S., \& Brazelton, T.B. (1978). The infant's response to entrapment between contradictory messages in face-toface interaction. Fournal of the American Academy of Child Psychiatry, 17, 1-13.

Tronick, E.Z., \& Cohn, J.F. (1989). Infant-mother face-to-face interaction: Age and gender differences in coordination and the occurrence of miscoordination. Child Development, 60, 85-92.

Vygotsky, L.S. (1962). Thought and language. Cambridge, MA: MIT Press.

Weinberg, M.K., \& Tronick, E.Z. (1994). Beyond the face: An empirical study of infant affective configurations of facial, vocal, gestural, and regulatory behaviors. Child Development, 65, 1503-1515.

Werner, H. (1948). Comparative psychology of mental development. New York: Follett.

Zigler, E. (1967). Familial mental retardation: A continuing dilemma. Science, 155, 292-298. 